\title{
Early Prediction of 3-month Survival of Patients in Refractory Cardiogenic Shock and Cardiac Arrest on Extracorporeal Life Support
}

\author{
Clément Delmas ${ }^{1,2}$, Jean-Marie Conil ${ }^{1}$, Simon Sztajnic ${ }^{1}$, Bernard Georges ${ }^{1}$, Caroline Biendel'2, Camille Dambrin ${ }^{3}$, Michel Galinier ${ }^{2}$, Vincent Minville ${ }^{1}$, \\ Olivier Fourcade', Stein Silva', Bertrand Marcheix ${ }^{3}$ \\ ${ }^{1}$ Intensive Care Unit, Department of Anesthesia and Critical Care, University Hospital of Toulouse, Departments of ${ }^{2}$ Cardiology and ${ }^{3}$ Cardiovascular Surgery, University \\ Hospital of Rangueil, Toulouse, France
}

\section{Abstract}

Background: Extracorporeal life support (ECLS) holds the promise of significant improvement of the survival of patient in refractory cardiogenic shock (CS) or cardiac arrest (CA). Nevertheless, it remains to be shown to which extent these highly invasive supportive techniques could improve long-term patient's outcome. Methods: The outcomes of 82 adult ECLS patients at our institution between January 2012 and December 2013 were retrospectively analyzed. Results: Patients were essentially men (64.7\%) and are 54 years old. Preexisting ischemic (53.7\%) and dilated cardiomyopathy (14.6\%) were frequent. ECLS indications were shared equally between CA and CS. ECLS-specific adverse effects as hemorrhage (30\%) and infection (50\%) were frequent. ECLS was effective for 43 patients (54\%) with recovery for $35(43 \%), 5(6 \%)$ heart transplant, and $3(4 \%)$ left ventricular assist device support. Mortality rate at 30 days was 59.8\%, but long-term and 3-month survival rates were similar of $31.7 \%$. Initial plasma lactate levels $>5.3 \mathrm{mmol} / \mathrm{L}$ and glomerular filtration $\mathrm{rate}<43 \mathrm{ml} / \mathrm{min} / 1.73 \mathrm{~m}{ }^{2}$ were significantly associated with 3-month mortality (risk ratio [RR] 2.58 [1.21-5.48]; $P=0.014$; RR 2.10 [1.1-4]; $P=0.024$, respectively). Long-term follow-up had shown patients paucisymptomatic (64\% New York Heart Association 1-2) and autonomic (activities of daily living [ADL] score $6 \pm 1.5$ ). Conclusion: In case of refractory CA or CS, lactates and renal function at ECLS initiation could serve as outcome predictor for risk stratification and ECLS indication.

Keywords: Cardiac arrest, cardiogenic shock, extracorporeal life support, extracorporeal membrane oxygenation

\section{INTRODUCTION}

Despite advances in intensive care medicine, the development of new pharmacological agents and early revascularization in case of ischemic etiology and treatment of cardiogenic shock (CS) and cardiac arrest (CA) remains difficult. ${ }^{[1,2]}$ They remain the leading cause of death in hospitalized patients regardless of etiology, and mortality at 30 days or 1 year is high of $50 \%$ for $\mathrm{CS},{ }^{[3]}$ or more than $80 \%$ in terms of CA. ${ }^{[4]}$ In these cases, inotropes and vasopressors could be useful but have been plagued by serious concerns regarding increased morbidity and mortality ${ }^{[5]}$ That's why, different hemodynamic supports have been used since the 1950s, but results are few, inconclusive, or negative for some. The International guidelines are only of limited use because of their lack of clear positioning and it exists only expert consensus and registries as reference. ${ }^{[6-9]}$ Empirically, extracorporeal life

\begin{tabular}{|l|l|}
\hline \multicolumn{3}{|c|}{ Access this article online } \\
\hline Quick Response Code: & Website: \\
& www.ijccm.org \\
& \\
&
\end{tabular}

support (ECLS) assumes an ever increasingly important place in the management of these patients. However, patient's selection is difficult even though ECLS requires considerable financial and human resources and should be allocated to patients in an appropriate and resource efficient manner. In this context, identification of factors associated with survival is required to optimize indications and nonindications. The objective of this study was to describe outcomes of patients which benefit to ECLS for refractory CA or CS in our tertiary teaching hospital. In parallel, we needed to identify

Address for correspondence: Dr. Clément Delmas, Intensive care Unit, University Hospital of Toulouse - Rangueil, 1 Avenue Jean Poulhes 31059 Toulouse Cedex, France. E-mail: delmas.clement@chu-toulouse.fr

This is an open access article distributed under the terms of the Creative Commons Attribution-NonCommercial-ShareAlike 3.0 License, which allows others to remix, tweak, and build upon the work non-commercially, as long as the author is credited and the new creations are licensed under the identical terms.

For reprints contact: reprints@medknow.com

How to cite this article: Delmas C, Conil JM, Sztajnic S, Georges B, Biendel C, Dambrin C, et al. Early prediction of 3-month survival of patients in refractory cardiogenic shock and cardiac arrest on extracorporeal life support. Indian J Crit Care Med 2017;21:138-45. 
the predictor of survival at 3 months and assessed long-term clinical condition.

\section{Methods}

\section{Patients}

We retrospectively analyzed data of 82 adult patients who had received ECLS in our university hospital for refractory CA or CS between January 2012 and December 2013.

Indications and timing for ECLS were determined by practitioners (intensivists, cardiologists, and cardiac surgeons) in charge of the patient.

ECLS contraindications were standard, including recent cerebral hemorrhage and other contraindications to anticoagulation, patients older than 75 years old, high comorbidities with chronic organ dysfunction (e.g., cirrhosis, emphysema, and respiratory failure) or advanced disease with a life expectancy of $<5$ years (e.g., terminal malignancy), and patients who had previously signed "do-not-resuscitate" orders. ${ }^{[10]}$

All patients included for refractory CS displayed the following signs: signs and symptoms of organ hypoperfusion (cool peripheries, oliguria, confusion, etc.) and at least one of the following parameters: systolic blood pressure $\leq 90 \mathrm{mmHg}$ and/or cardiac index $<2.2 \mathrm{~L} / \mathrm{min} / \mathrm{m}^{2}$ for at least $30 \mathrm{~min}$, or necessity of vasopressor to maintain systolic blood pressure $>90 \mathrm{mmHg}$, and evidence of elevated filling pressures (pulmonary congestion on examination or chest X-ray).$^{[9]}$

Patients included for CA were witnessed to have suffered an arrest of presumed cardiac origin, who subsequently received cardiopulmonary resuscitation (CPR) for longer than 15-20 min. ${ }^{[11]}$ CA could be in-hospital or out-of-hospital CA.

\section{Extracorporeal life support management}

ECLS system consisted mainly of a heparin-bound centrifugal pump and a hollow-fiber microporous membrane oxygenator. Cannulations were predominantly femorofemoral (15-19 Fr arterial and 23-29 Fr venous cannula) performed using modified Seldinger surgical technique with an additional 7-Fr catheter inserted for distal limb perfusion. Venous cannula position was confirmed by echocardiography and Chest X-ray.

Extracorporeal blood flow was adjusted to maintain adequate systemic blood flow and oxygen supply as monitored by mean arterial pressure, $\mathrm{SvO}_{2}$, urine output, and lactate concentration. The pump flow was initially set at approximately $2-3 \mathrm{~L} / \mathrm{min}$. Fluid and vasopressors were secondly infused to maintain a mean arterial blood pressure of $\geq 65 \mathrm{mmHg}$ and flow rate of $3.5-4 \mathrm{~L} / \mathrm{min}$ to preserve organ function. ${ }^{[10]}$ Dobutamine was systematically added to facilitate ventricular decompression in order to minimize the risk of acute pulmonary edema and intraventricular clotting. Intra-aortic balloon pump (IABP) was utilized at the discretion of the physician in charge of the patient. Heparin was infused to maintain an activated clotting time between 180 and $220 \mathrm{~s}$ in the absence of hemorrhage.
All patients were initially sedated and mechanically ventilated with standard protective ventilation (tidal volume $6-8 \mathrm{ml} / \mathrm{kg}$ and positive end-expiratory pressure $8-10 \mathrm{~cm} \mathrm{H}_{2} \mathrm{O}$ ). Mild hypothermia $\left(33-34^{\circ} \mathrm{C}\right)$ was initiated in cases of CA.

Serial biological assessments and echocardiographic evaluation were performed to assess organ dysfunction and myocardial function recovery.

The circuit was checked daily by experienced perfusionists and changed when significant fibrin deposition or clots accumulated on the membrane, hemolysis or thrombocytopenia, or blood oxygenation sharply declined.

When a pulsatile arterial waveform appeared and was associated with hemodynamic stability without multiorgan dysfunction for at least $24 \mathrm{~h}$, an ECLS weaning trial was undertaken by progressively decreasing pump flow to $1.5-2 \mathrm{~L} / \mathrm{min}$. Then, when left ventricular ejection fraction was $\geq 30 \%$, aortic time velocity integral was $\geq 10 \mathrm{~cm}$, and the patient's hemodynamic status had remained stable for $2-4 \mathrm{~h}$; the machine was removed with surgical repair of the femoral or axillar access. Patients were considered weaned if they were living at $24 \mathrm{~h}$ after withdrawal of the assistance. When ECLS weaning was impossible, bridging to a ventricular assist device or transplantation was considered.

\section{Data collection}

Detailed pre-ECLS data including age, gender, coronary risk factors, prior heart disease, etiology of CA or CS, initial biological data, and Simplified Acute Physiology Score (SAPS) $\mathrm{II}^{[12]}$ at the time of ECLS initiation were retrospectively collected.

In-hospital ECLS-associated complications were noted, such as acute limb ischemia, infection, hemorrhage, pulmonary edema, acute renal injury requiring dialysis, and ECLS dysfunction.

The main outcome variable was 3-month survival, but we also analyzed 30-day survival rates and long-term survival. Other outcome measures included duration of Intensive Care Unit (ICU) stay and total hospitalization.

To assess long-term clinical condition, patients still living in March 2014 were contacted by telephone and evaluated according to the activities of daily living (ADL) and the New York Heart Association (NYHA) dyspnea scores.

\section{Ethics}

The study protocol was approved by our Institutional Ethics and Research Committee ( $n$ 2013-2014). Since the demographic, physiology, and in-hospital outcome data analyses are used routinely and did not modify existing diagnostic or therapeutic strategies, the need for informed consent was waived. However, consent for long-term survivors was obtained for NYHA and ADL assessment.

\section{Statistical analyses}

After an initial collection of descriptive statistics, the study population was divided into 2 groups using survival 
at 3 months. Patient characteristics were compared using parametric or nonparametric tests depending on the normal distribution of the values (Kolmogorov-Smirnov test). Data were presented as a median and $95 \%$ confidence interval or ratio. This univariate analysis step was used to identify the variables which were statistically different in the two groups. Kaplan-Meier curve was also constructed at this univariate analysis phase to estimate mortality at 3 months. The discriminant value of survival at 3 months for each of the covariates of interest was assessed by measuring the area under the receiver operating characteristic (ROC) curves. The areas under the ROC curves were compared with the Wilcoxon signed-rank test. The best thresholds with their corresponding likelihood ratios (negative and positive) were calculated using Youden's index. For each covariate, the "gray zone" was determined using a two-step procedure as described by Cannesson et al. ${ }^{[13]}$

To identify risk factors independently associated with 3-month mortality, multivariable Cox proportional-hazard model was used. In this approach, if collinearity is present, the less influential variable is eliminated. A backward elimination was used to do this: its principle is to include all selected variables and to progressively remove insignificant ones. The internal validation of the model has been executed using a resampling Monte Carlo technique (Bootstrap).

The statistical analysis was performed using MedCalc ${ }^{\circledR}$ Version 15 statistical software (Mariakerke, Belgium) except for bootstrapping which was performed on SPSS 20.0 (IBM Corp. Released 2011; IBM SPSS Statistics for Windows, Version 20.0, Armonk, NY, USA). $P<0.05$ was considered statistically significant.

\section{RESULTS}

\section{Patients}

During this 2-year period, 82 adult patients benefited from ECLS in our institution. Baseline characteristics of our population are described in Table 1. Patients were essentially male with a median age of 54 years. Cardiovascular risk factors were frequent and classic in more than one-third of the patients.

Eighteen (22\%) patients had no prior heart disease, $44(53.7 \%)$ had ischemic cardiomyopathy, 12 (14.6\%) dilated cardiomyopathy, and $9(11.0 \%)$ others cardiomyopathies without any difference between survivors and nonsurvivors at 3 months.

ECLS indications were distributed equally between CA and CS $(n=43 ; 52.4 \%)$.

Etiologies for CS and CA were divided between end-stage cardiac failure, acute cardiac failure, and postcardiotomy shock, of which 6 were postcardiac transplant. Acute coronary syndrome was frequent $(n=29 ; 35.4 \%)$. Others etiologies were less frequent: 9 electrical storms, 4 poisoning, 3 pulmonary embolisms, 2 acute respiratory distress syndromes, 1 hypothermia, and 1 electrocution.
For CA patients, 27 (69.2\%) ECLS were initiated under continuous CPR.

Femorofemoral cannulation was used for 77 patients (94\%) while femoro-axillar cannulation was used for 5 patients $(6 \%)$. At the time of ECLS initiation, $12(15 \%)$ patients were under IABP and 1 was under Impella 5.0 ${ }^{\circledR}$.

SAPS II at admission (59 [52-65]) was high, reflecting disease severity (SAPS II at 30-day predicted mortality higher than $65 \%$ ). Elevated blood lactate, bilirubin and troponin, and reduced serum bicarbonates, prothrombin activity, and estimated glomerular filtration rate (eGFR) by chronic kidney disease-epidemiology collaboration equation, also reflected severe multiorgan failure at ECLS onset.

\section{Extracorporeal life support complications}

ECLS complications are described in Table 2. ECLS support was complicated by acute limb ischemia in $12 \%$ of patients: half required surgical treatment and half required removal of the ECLS system. Hemorrhage was found in one-third of the patients with diffuse bleeding for $15(18.3 \%)$ and bleeding on the cannula site for $9(11.0 \%)$. However, in the end, only 4 patients (4.9\%) required surgical repair. Four patients were diagnosed with stroke $(4.9 \%)$.

Infections were frequent concerning more than $90 \%$ of survivors, especially of pulmonary origin and septicemia.

Of 11 patients (13.4\%) with pulmonary edema, 10 (12.2\%) required a discharge of the left ventricle with atrial septostomy for 7 patients $(8.5 \%)$, IABP for $2(2.4 \%)$, Impella $5.0^{\circledR}$ for $1(1.2 \%)$, and femoro-axillar conversion for $1(1.2 \%)$. We identified 3 (3.7\%) machine dysfunctions by clotting of the oxygenator without consequences for the patient.

\section{In-hospital outcomes}

One-quarter of the deaths $(n=14)$ occurred on the day of ECLS initiation, 7 on the $1^{\text {st }}$ day, and 4 on the $2^{\text {nd }}$ day. Early deaths during the first $48 \mathrm{~h}$ represented $44.6 \%$ of total deaths and were mainly due to refractory multiorgan failure and $80 \%(n=20)$ concerned the CA population $(P<0.001)$. In total, $60.7 \%(n=34)$ of deaths occur before day eight.

Thirty-five patients $(42.7 \%)$ were successfully weaned from ECLS after heart recovery, but only 29 (35.4\%) were discharged alive from the ICU.

\section{Thirty-day outcome}

Mortality at 30-day was high $59.8 \%(n=49)$ with a significant statistical difference between CA population $(76.9 \%, n=30)$ and CS population $(53.5 \%, n=23 / P=0.025)$, but we did not find any difference between in-hospital and out-of-hospital CA, or if ECLS was implanted under continuous CPR.

\section{Three-month outcome}

CA was associated with the highest mortality at 3 months (79.5\%), especially if ECLS was performed during external chest compressions $(81.5 \%)$ but without significance $(P=0.057)$. 
Table 1: Baseline characteristics of extracorporeal life support population: Comparative analysis between survivors and nonsurvivors at 3 months

\begin{tabular}{|c|c|c|c|c|}
\hline & All $(n=82)$ & Nonsurvivors at 3 months $(n=56)$ & 3 months survivors $(n=26)$ & $P$ \\
\hline Age (years), median $(95 \% \mathrm{CI})$ & $54(51-57)$ & $56(53-58)$ & $50(46-55)$ & 0.046 \\
\hline Male, $n(\%)$ & $53(64.6)$ & $36(64.3)$ & $17(65.4)$ & 1 \\
\hline \multicolumn{5}{|l|}{ Cardiovascular risk factors, $n(\%)$} \\
\hline Diabetes mellitus & $17(20.7)$ & $14(25.5)$ & $3(11.5)$ & 0.242 \\
\hline Hypertension & $30(36.6)$ & $19(33.9)$ & $11(42.3)$ & 0.623 \\
\hline Tobacco & $36(43.9)$ & $25(44.6)$ & $11(42.3)$ & 0.81 \\
\hline Dyslipidemia & $30(36.6)$ & $20(35.7)$ & $10(38.5)$ & 0.806 \\
\hline BMI $\left(\mathrm{kg} / \mathrm{m}^{2}\right)$, median $(95 \% \mathrm{CI})$ & $26(24-28)$ & $27(24-29)$ & $25(22-28)$ & 0.475 \\
\hline \multicolumn{5}{|l|}{ Indications of ECLS support, $n(\%)$} \\
\hline $\mathrm{CA}$ & $39(47.6)$ & $31(55.4)$ & $8(46.4)$ & 0.057 \\
\hline Out of hospital CA & $18(22)$ & $15(16.8)$ & $3(11.5)$ & 0.4265 \\
\hline Under CPR & $27(32.9)$ & $22(39.3)$ & $5(19.2)$ & 0.083 \\
\hline End terminal heart failure & $11(13.4)$ & $7(12.5)$ & $4(15.4)$ & 0.736 \\
\hline Acute heart failure & $12(14.6)$ & $7(12.5)$ & $5(19.2)$ & 0.506 \\
\hline Postcardiotomy CS & $20(24.4)$ & $14(25)$ & $6(23.1)$ & 0.99 \\
\hline \multicolumn{5}{|l|}{ Biological data; median $(95 \% \mathrm{CI})$} \\
\hline Sodium $(\mathrm{mmol} / \mathrm{L})$ & $140(136-141)$ & $141(136-143)$ & $137(133-141)$ & 0.095 \\
\hline Potassium (mmol/L) & $4(3.8-4.2)$ & $4.0(3.7-4.2)$ & $4.0(3.5-4.9)$ & 0.475 \\
\hline Hemoglobin $(g / d L)$ & $11.1(10.6-11.9)$ & $11(9.9-11.4)$ & $12.1(10.8-13)$ & 0.031 \\
\hline eGFR $\left(\mathrm{mL} / \mathrm{min} / 1.73 \mathrm{~m}^{2}\right)$ & $43.5(39.7-51.1)$ & $40.5(35.5-45.1)$ & $54.5(44.6-64.5)$ & 0.024 \\
\hline $\mathrm{pH}$ & $7.25(7.2-7.29)$ & $7.24(7.17-7.29)$ & $7.27(7.20-7.33)$ & 0.381 \\
\hline Serum bicarbonate $(\mathrm{mmol} / \mathrm{L})$ & $18(16-19.7)$ & $17(15-18.1)$ & $20.5(17.6-21)$ & 0.029 \\
\hline Blood lactate concentration $(\mathrm{mmol} / \mathrm{L})$ & $9(6.2-10)$ & $10.8(7.4-13.4)$ & $4.4(4.0-10)$ & 0.022 \\
\hline Aspartate aminotransferase (IU/L) & $257(180.5-494.8)$ & $432(217.3-537.1)$ & $168.5(77.5-457.3)$ & 0.166 \\
\hline Alanine aminotransferase (IU/L) & $156(82.1-245.7)$ & $204(101.7-347.0)$ & $70.5(38.2-237.1)$ & 0.021 \\
\hline Prothrombin time $(\%)$ & $52(45-57)$ & $53(43.3-60.7)$ & $49.5(42.9-57.5)$ & 0.281 \\
\hline Activated clotting time & $2.3(1.9-3.4)$ & $2.6(2.1-4.4)$ & $1.9(1.3-2.6)$ & 0.066 \\
\hline Factor V $(\%)$ & $38(33.1-47)$ & $36(22-52)$ & $39(35-52)$ & 0.424 \\
\hline Fibrinogen $(\mathrm{g} / \mathrm{L})$ & $2.8(2.4-3.3)$ & $2.9(2.2-3.6)$ & $2.8(2.3-3.5)$ & 0.749 \\
\hline \multicolumn{5}{|l|}{ Severity score and outcome parameters } \\
\hline SAPS II score, median $(95 \%$ CI $)$ & $59(52-65)$ & $65(55-73)$ & $48(42-61)$ & 0.04 \\
\hline Length of ECLS support (days) & $4(3-5)$ & $3(1-5)$ & $6(4-8)$ & 0.024 \\
\hline Total hospital stay (days) & $18(11-26)$ & $6(2-17)$ & $49(34-78)$ & $<0.001$ \\
\hline
\end{tabular}

Table 2: Extracorporeal life support complications: Analysis of the overall population and comparative analysis between survivors and nonsurvivors at 3 months

\begin{tabular}{|c|c|c|c|c|}
\hline & $\begin{array}{l}\text { Total population } \\
(n=820), n(\%)\end{array}$ & $\begin{array}{l}\text { Nonsurvivors at } 3 \text { months } \\
(n=56), n(\%)\end{array}$ & $\begin{array}{c}3 \text { months survivors } \\
(n=26), n(\%)\end{array}$ & $P$ \\
\hline Hemorragia & $27(32.9)$ & $17(30.4)$ & $10(38.4)$ & 0.614 \\
\hline Acute pulmonary edema & $11(13.4)$ & $9(16)$ & $2(7.7)$ & 0.489 \\
\hline Acute limb ischemia & $10(12.2)$ & $3(5.4)$ & $7(26.9)$ & $0.010^{*}$ \\
\hline Infections & $43(52.4)$ & $19(33.9)$ & $24(92.3)$ & $<0.001^{*}$ \\
\hline Pneumonia & $36(43.9)$ & $15(26.8)$ & $21(80.8)$ & $<0.001^{*}$ \\
\hline Septicemia & $14(17.1)$ & $3(5.4)$ & $11(42.3)$ & $<0.001^{*}$ \\
\hline
\end{tabular}

At 3 months, 26 (31.7\%) patients were alive [Figure 1] with 4 transplanted, and 3 under left ventricular assist device (LVAD).

\section{Factors associated with 3-month mortality}

Survivors were younger, had better renal function, and presented with fewer signs of shock at ECLS onset as demonstrated by lower SAPS II score and lactate levels, lower alanin amino transferase (ALAT), and higher serum bicarbonate.

As shown in Figure 2, discriminative value of significant variables was moderate. Blood lactate concentration-related ROC curves 
revealed an area under the curve (AUC) at $0.66(0.54-0.77)$ with $76 \%$ sensibility, $56 \%$ specificity, and a threshold value higher than $5.3 \mathrm{mmol} / \mathrm{L}$ (gray zone: $2.5-18.0$ ). For eGFR, AUC was at $0.66(0.54-0.76)$ with $61 \%$ sensibility, $73 \%$ specificity, and a threshold eGFR value $\leq 43 \mathrm{ml} / \mathrm{min} / 1.70 \mathrm{~m}^{2}$ (gray zone: $26-84$ ).

Survivors had a longer length of ECLS support and total hospital stay.

Multivariate analysis using a Cox model, taking into account all covariates, shows an influence of three factors. The independent predictors of 3-month mortality [Table 3] evaluated at the time of ECLS onset included elevated blood lactate levels $>5.3 \mathrm{mmol} / \mathrm{L}$ and eGFR alteration $\leq 43 \mathrm{ml} / \mathrm{min} / \mathrm{m}^{2}$. For these two covariates, risk ratios (RRs) were $2.58(1.21-5.48)(P=0.0142)$ and $2.1(1.1-4)(P=0.0239)$, respectively. Moreover, multivariate analysis revealed an important predictor of survival, which is ECLS weaning success with a RR of $0.0797(0.036-0.18)$ $(P<0.0001)$ while CA did not reach a significant value. With a bootstrap technique, this model was validated by Monte Carlo simulation on 3000 patients (1000 by covariate) with statistical significance (bilateral analysis) for these three covariates $(P=0.013$ for lactate blood threshold, 0.024 for eGFR, and $P<0.0001$ for ECLS weaning success).

\section{Long-term outcomes}

Characteristics of long-term survivors are shown in Table 4. Survivors were predominantly male $(65.4 \%)$ with a long hospital stay (42 days [32-63]) and only $23.1 \%$ were discharged from hospital at 30 days. Of the long-term survivors, $19.2 \%$ were transplanted and $11.5 \%$ were under LVAD support.

Of the 26 survivors, 25 (96\%) were evaluated on ADL score, NYHA classification, and work. The majority of patients were paucisymptomatic (64\% class 1 or 2 of NYHA) and autonomous (ADL score 6 ). Nineteen (73\%) patients returned home, $3(12 \%)$ were in rehabilitation centers, $3(12 \%)$ were still hospitalized, and $1(4 \%)$ was lost to follow-up. Only nine considered themselves handicapped, although 6 (23.1\%) presented with neurological sequelae (ICU tetraparesia or stroke), $3(11.5 \%)$ suffered from anxiodepressive disorders, and $2(7.7 \%)$ had tracheotomies.

\section{Discussion}

We report here retrospectively our 2-year experience with ECLS in refractory CA and CS on 82 patients, with 30-day survival of $40.2 \%$ and 3 -month survival of $31.7 \%$. In our population, lactate $>5.3 \mathrm{mmol} / \mathrm{L}$ and $\mathrm{eGFR}<43 \mathrm{ml} / \mathrm{min} / 1.73 \mathrm{~m}^{2}$ were predictive of 3-month mortality, although ECLS weaning success was protective.

\section{Thirty-day and 3-month mortality}

As previously described, ${ }^{[14-17]}$ early mortality was significant mainly due to refractory multiorgan failure, and it concerned predominantly the CA population. This most likely reflects a group of patients suffering from irreversible end-organ hypoperfusion, signaling poor ECLS indications. ${ }^{[15-17]}$

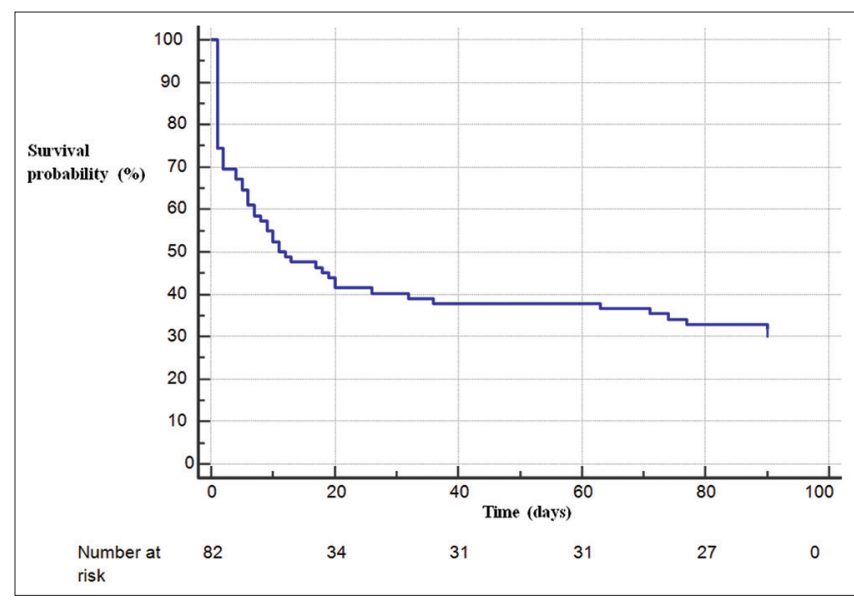

Figure 1: Three-month prognosis of patients supported by extracorporeal life support. Early mortality was important since $30.5 \%$ of patients died within the first $48 \mathrm{~h}$, which corresponds to $44.7 \%$ of total deaths.

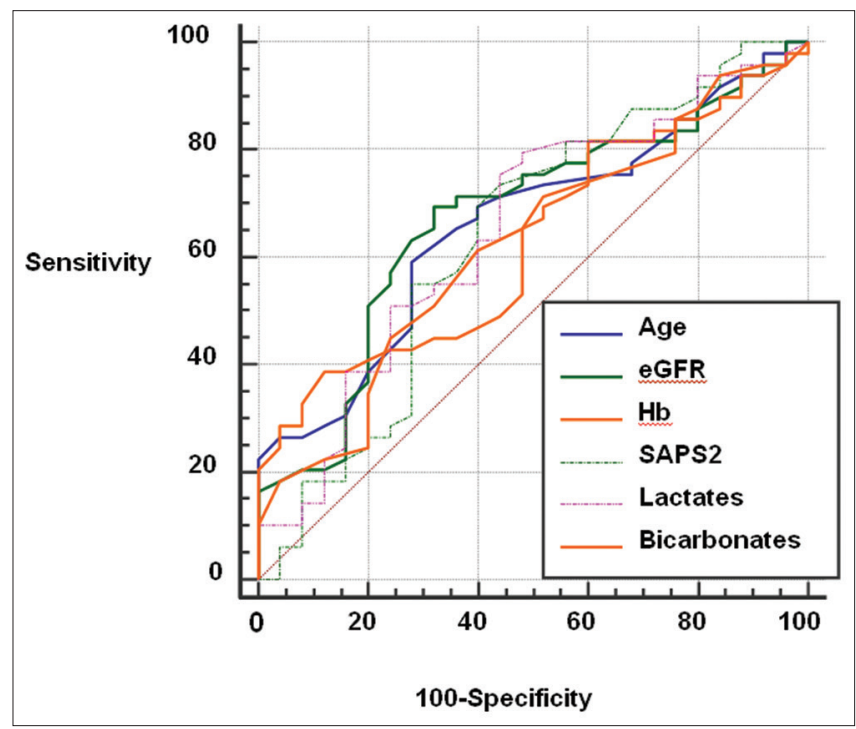

Figure 2: Receiver operating characteristic curves for prognosis factors of 3-month mortality. eGFR: Estimated glomerular filtration rate by CKD-EPI equation, Hb: Hemoglobin, Age: AUC 0.64 (0.52-0.74), eGFR: AUC 0.66 (0.54-0.76); Hemoglobin: AUC 0.65 (0.53-0.75); IGS2: AUC 0.64 (0.53-0.75); Lactates: AUC 0.66 (0.54-0.77); Bicarbonates: AUC 0.65 (0.54-0.76); AUC: Area under the curve.

\begin{tabular}{|c|c|c|c|}
\hline & Risk ratio & $P$ & $95 \% \mathrm{Cl}$ \\
\hline \multicolumn{4}{|l|}{ Significant covariates } \\
\hline ECLS weaning success & 0.0797 & $<0.0001$ & $0.0356-0.1783$ \\
\hline Blood lactate $>5.3 \mathrm{mmol} / \mathrm{L}$ & 2.5796 & 0.0142 & $1.2145-5.479$ \\
\hline $\mathrm{eGFR} \leq 43 \mathrm{ml} / \mathrm{min} / 1.70 \mathrm{~m}^{2}$ & 2.1048 & 0.0239 & $1.1070-4.0018$ \\
\hline \multicolumn{4}{|l|}{$\begin{array}{l}\text { Nonincluables variables in } \\
\text { the model }\end{array}$} \\
\hline $\mathrm{CA}$ & 1.562 & 0.146 & $0.8591-2.8403$ \\
\hline $\mathrm{Hb} \leq 12.6 \mathrm{~g} / \mathrm{L}$ & 1.018 & 0.962 & $0.4841-2.1417$ \\
\hline
\end{tabular}

eGFR: Estimated glomerular filtration rate by CKD-EPI equation; Hb: Hemoglobin; CI: Confidence interval; CKD: Chronic kidney disease; EPI: Epidemiology collaboration; ECLS: Extracorporeal life support; CA: Cardiac arrest 


\begin{tabular}{lc}
\hline Table 4: Characteristics of long-term survivors & $(\boldsymbol{n}=\mathbf{2 6})$ \\
\hline Long-term survivors & $\boldsymbol{n}=\mathbf{2 6}$ \\
\hline Male, $n$ (\%) & $17(65.4)$ \\
Total hospital stay (days), median $(95 \%$ CI) & $42(32-63)$ \\
Total ICU stay (days), median $(95 \%$ CI) & $32(23-38)$ \\
Hospitalization output to questionnaire delay (days), & $207(133-291)$ \\
median (95\% CI) & \\
Discharged from ICU at 30 days, $n$ (\%) & $12(46.15)$ \\
Discharged from hospital at 30 days, $n$ (\%) & $6(23.1)$ \\
Rehospitalization during the 3 months period, $n$ (\%) & $10(38.5)$ \\
Transplantation post-ECLS, $n$ (\%) & $5(19.2)$ \\
LVAD, $n$ (\%) & $3(11.5)$ \\
NYHA status, $n$ (\% on 25) & $10(40)$ \\
1 & $6(24)$ \\
2 & $7(31.8)$ \\
3 & $2(9.1)$ \\
4 & $6 \pm 1.5$ \\
ADL score (1-6) for 25 patients; mean \pm SD & $9(36)$ \\
Handicap, $n$ (\% on 25) & $5(20)$ \\
Back-to-work, $n$ (\% on 25) & \\
\hline On the 26 survivors, 25 (96\%) were evaluated on their ADL score, \\
NYHA classification and their work. Handicap: Disability was reported \\
by the patient (ICU tetraparesia, stroke, anxiodepressive disorders, etc.). \\
ADL: Activities of daily living; NYHA: New York Heart Association; \\
ICU: Intensive Care Unit; LVAD: Left ventricular assist device; \\
SD: Standard deviation; ECLS: Extracorporeal life support \\
\end{tabular}

With a 30 -day mortality of $59.8 \%$ and 3 -month mortality of $68.3 \%$, we are in accordance with published data (30-day mortality of $37 \%-76 \%{ }^{[18-20]}$ and 3-month mortality of $45 \%-65 \%{ }^{[14,21]}$ ) confirming the sick severity of ECLS supported CA or CS patients.

\section{Complications}

Complications were not associated with poor outcomes in our series contrary to several studies. ${ }^{[17,22]}$ Acute pulmonary edema resulting from left ventricular overload is a devastating complication affecting only $13.4 \%$ of our population compared to previous reports. ${ }^{[16,18]}$ Unfortunately, we failed to identify any preoperative risk factors that would predict the onset of pulmonary edema. In our institution, no prespecified protocol exists and different left ventricular discharge methods have been used. Contrary to other teams, atrioseptostomy was the technique most used. ${ }^{[14,16]}$

Others ECLS complications were frequents as already demonstrated, including infections, acute limb ischemia, and bleeding. ${ }^{[16,18]}$ These complications were not associated with a higher mortality and seemed to be correlated to a lengthened duration of ECLS support. This result is related to the time under ECLS support (4 days) as reported in literature (0.3-10 days $)^{[14-16,18,23]}$ and was significantly lower for CA population and longer for survivors.

\section{Prognostic factors of 3-month mortality}

Interestingly, our study focalizes on pre-ECLS prognostic factors for 3-month mortality and not for 30-day or in-hospital mortality. Severe multiorgan failure at ECLS implantation was strongly associated with an unfavorable outcome as previously described. ${ }^{[14,18,22,24,25]}$

Blood lactate concentration, which is a marker of acute physiologic derangement and severe cellular hypoxia, is the best prognostic factors of 3-month mortality in our ECLS patients with a cutoff of $5.3 \mathrm{mmol} / \mathrm{L}$. These results are consistent with previous reports although different cutoffs are noted in other studies. ${ }^{[15,18,23,25,26]}$

Renal function with eGFR appears to be another strong prognostic factor of mortality as frequently described in literature, ${ }^{[18,22,25,26]}$ even if it is not ever noted. ${ }^{[23]}$ Our threshold of $43 \mathrm{ml} / \mathrm{min} / 1.73 \mathrm{~m}^{2}$ is consistent with clinical practice since it is the limit for inscription on emergency transplantation lists in France ("Agence de Biomédecine") and is in agreement with international guidelines. ${ }^{[27]}$ Renal failure may represent not only a marker of high-risk status in these patients but also a predisposing factor for potentially lethal postimplantation or posttransplantation complications. ${ }^{[25]}$

Although severity scores ${ }^{[12,28]}$ remain the essential tools used to assess the prognosis of ICU patients including those treated with ECLS, ${ }^{[19]}$ SAPS II was only predictive in univariate analysis in our series.

Even if CA does not reach significance in our series, it is a classical marker of poor prognosis. ${ }^{[14,15,18,25,29]}$ There was also no detectable relationship between indications for ECLS, age, weight, or other comorbidities on mortality, in contrast with others studies. ${ }^{[22-25]}$

It is not possible to know whether this represents preselection by clinicians of patients or whether our study was underpowered to detect an effect due to other comorbidities or clinical conditions.

Many prediction models for severe acute respiratory failure requiring ECMO have been published and externally validated over recent years; ${ }^{[30,31]}$ predictive scores for mortality prognostic on ECLS for cardiac failure are less frequent and less robust. ${ }^{[2,29,32]}$ Schmidt et al. recently published the SAVE score based on a large pre-ECLS assessment data extracted from the Extracorporeal Life Support Organization registry. ${ }^{[25]}$ However, scores, especially the SAVE score, are complex leading to limited clinical application. Some authors suggest that simpler scores would be equally effective and easier to apply. ${ }^{[26]}$

All of these observations reinforce the need for early recognition of patients rapidly progressing to refractory cardiac failure and who need immediate transfer to a medical-surgical center experienced in mechanical circulatory support to prevent multiorgan failure and futile indications as previously suggested. ${ }^{[14]}$

Extracorporeal life support weaning predictive of 3-month survival

In our series, $42.7 \%$ of patients were successfully weaned from ECLS although some authors report better weaning 
success. ${ }^{[16,19,24,33]}$ However, in these series, mortality in weaned patients was as high as $50 \%$ due to low number of bridge to assistance or transplant projects. ${ }^{[24]}$ In our population, 5 patients were transplanted, 3 assisted by an LVAD (Heartmate II $^{\circledR}$, Thoratec), and for patients who recovered, the survival rate at 3-month was high at $74.3 \%$. Postweaning deaths were secondary to insufficient recovery of the heart and/or organ failure, or ICU complications.

Nonsuccessfully weaned patients had a shorter duration of circulatory support (1.7 vs. 5.8 days) which is largely explained by the early deaths. Thus, prolonged support was found in this group for patients who had not recovered and were no longer accessible to a bridge (max support 15 days for weaned patient vs. 17 in nonweaned patients). These data raise a crucial question of timely withdrawal of ECLS support. Delay must be taken into consideration before evaluation of the patient for weaning, because clinicians must promote systemic hemodynamic restoration and correct multiorgan failure. Furthermore, a period for cardiac functional recovery through ECLS is necessary and could be the first goal in the majority of cases (electrical storm, myocarditis, posttransplantation CS). ${ }^{[16]}$ Rousse et al. found $80 \%$ success when weaning was attempted between day 4 and day $11 .^{[16]}$ Finally, neurological evaluation is necessary before bridge projects, especially for the CA population. ${ }^{[6]}$ Extended support periods expose patients to ICU and ECLS complications, which worsen prognosis. ${ }^{[16,17]}$ Timing of ECLS weaning is a major concern for critically ill patients rescued by ECLS for CA or CS. Factors could help in predicting weaning success or failure, but ECLS weaning remains complex and is performed without clear guidelines in most centers. Only a few recent studies address this topic and seek to find prognostic factors of weaning success to propose weaning protocols. ${ }^{[24,34]}$ In this tool, echocardiography seems to be of interest. ${ }^{[35,36]}$

Another finding of importance is that successful weaning from ECLS support was independently predictive of 3-month survival and positive outcome. Consistently, others had also demonstrated that successful ECLS weaning was strongly associated with in-hospital survival. ${ }^{[19,24]}$ Results are obvious since all patients who were not successfully weaned from ECLS usually died in hospital. ${ }^{[19]}$ Our data confirms the need of an initial clear project at the time of ECLS onset for each patient and the need to consider early-on a bridge in case of ECLS weaning difficulty.

\section{Long-term prognosis and functional status}

We found here the same survival at 3 months and at long-term follow-up (207 [133-291] days) with 26 survivors (31.7\%) which confirms the risk of death of these patients, focusing on pre-ECLS and initial ECLS support period (day 1-4). Similarly, previous studies looking at long-term survival have ranged between $18 \%$ and $48 \%{ }^{[34,37]}$ If we analyze only ECLS weaned patients, survival is $74.3 \%$ at 3 months and at long-term follow-up in our series.

We described a satisfactory functional status in survivors since $64 \%$ were NYHA class 1 or 2 , and the vast majority was autonomous with an ADL score of $6 \pm 1.5$. However, only a few survivors went back to work (20\%). Combes et al. had described that ECLS patients had significantly lower mean SF-36 scores (physical, general health, and social functioning) compared to French, age- and sex-matched normal controls but were similar with NYHA class III heart failure patients or chronically hemodialyzed patients or ARDS survivors. ${ }^{[14]}$

\section{Study limitations}

We present here a retrospective and monocentric study with only 82 patients. Thus, it was rather difficult to make a conclusion with respect to the findings from any individual subgroup. Moreover, we chose to study CA and CS in the same analysis as these populations are fairly close in terms of etiology (ECLS implantation under CPR represent only a third of the total population). Likewise, during this period, we did not have a standardized protocol for indications and management of ECLS supported patients, which had changed during the study period, but we did not analyze results by months or years.

\section{Conclusion}

Our study shows that for patients with CA or CS refractory to conventional treatment, ECLS support might provide a reasonable chance of long-term survival. Blood lactate concentrations $>5.3 \mathrm{mmol} / \mathrm{L}$ and $\mathrm{eGFR} \leq 43 \mathrm{ml} / \mathrm{min} / 1.73 \mathrm{~m}^{2}$ at ECLS initiation are prognostic of 3-month mortality, which is also influenced by ECLS weaning success. These factors might serve as assessment parameters for risk stratification in clinical settings for predicting prognostic outcome regarding ECLS support. However, further prospective, multicentered, and randomized controlled investigations are required for evaluating the additional benefit of ECLS support in clinical setting of CS and CA.

\section{Financial support and sponsorship}

Nil.

\section{Conflicts of interest}

There are no conflicts of interest.

\section{References}

1. Thiele H, Ohman EM, Desch S, Eitel I, de Waha S. Management of cardiogenic shock. Eur Heart J 2015;36:1223-30.

2. Goldberg RJ, Spencer FA, Gore JM, Lessard D, Yarzebski J. Thirty-year trends (1975 to 2005) in the magnitude of, management of, and hospital death rates associated with cardiogenic shock in patients with acute myocardial infarction: A population-based perspective. Circulation 2009;119:1211-9.

3. Aissaoui N, Puymirat E, Tabone X, Charbonnier B, Schiele F, Lefèvre T, et al. Improved outcome of cardiogenic shock at the acute stage of myocardial infarction: A report from the USIK 1995, USIC 2000, and FAST-MI French nationwide registries. Eur Heart J 2012;33:2535-43.

4. Strömsöe A, Svensson L, Axelsson ÅB, Claesson A, Göransson KE, Nordberg P, et al. Improved outcome in Sweden after out-of-hospital cardiac arrest and possible association with improvements in every link in the chain of survival. Eur Heart J 2015;36:863-71.

5. Abraham WT, Adams KF, Fonarow GC, Costanzo MR, Berkowitz RL, LeJemtel $\mathrm{TH}$, et al. In-hospital mortality in patients with acute decompensated heart failure requiring intravenous vasoactive medications: An analysis from the acute decompensated heart failure 
national registry (ADHERE). J Am Coll Cardiol 2005;46:57-64.

6. Windecker S, Kolh P, Alfonso F, Collet JP, Cremer J, Falk V, et al. 2014 ESC/EACTS Guidelines on myocardial revascularization: The Task Force on Myocardial Revascularization of the European Society of Cardiology (ESC) and the European Association for Cardio-Thoracic Surgery (EACTS) Developed with the special contribution of the European Association of Percutaneous Cardiovascular Interventions (EAPCI). Eur Heart J; 35:2541-619.

7. Yancy CW, Jessup M, Bozkurt B, Butler J, Casey DE Jr., et al. 2013 ACCF/AHA guideline for the management of heart failure: A report of the American College of Cardiology Foundation/American Heart Association Task Force on practice guidelines. Circulation 2013;128:e240-327.

8. McMurray JJ, Adamopoulos S, Anker SD, Auricchio A, Böhm M, Dickstein K, et al. ESC Guidelines for the diagnosis and treatment of acute and chronic heart failure 2012: The Task Force for the Diagnosis and Treatment of Acute and Chronic Heart Failure 2012 of the European Society of Cardiology. Developed in collaboration with the Heart Failure Association (HFA) of the ESC. Eur Heart J 2012;33:1787-847.

9. Levy B, Bastien O, Karim B, Cariou A, Chouihed T, Combes A, et al. Experts' recommendations for the management of adult patients with cardiogenic shock. Ann Intensive Care 2015;5:52.

10. Extracorporeal Life Support Organization, editor. ELSO Guidelines for Cardiopulmonary Extracorporeal Life Support. Version 1. $3^{\text {rd }}$ ed. Ann Arbor, MI, USA; 2013.

11. Riu B, Adnet F, Baud F, Cariou A, Carli P, Combes A, et al. Guidelines for indications for the use of extracorporeal life support in refractory cardiac arrest. French ministry of health. Ann Fr Anesth Reanim 2009;28:182-90

12. Knaus WA, Draper EA, Wagner DP, Zimmerman JE. APACHE II: A severity of disease classification system. Crit Care Med 1985;13:818-29.

13. Cannesson M, Le Manach Y, Hofer CK, Goarin JP, Lehot JJ, Vallet B, et al. Assessing the diagnostic accuracy of pulse pressure variations for the prediction of fluid responsiveness: A "gray zone" approach. Anesthesiology 2011;115:231-41.

14. Combes A, Leprince P, Luyt CE, Bonnet N, Trouillet JL, Léger P, et al. Outcomes and long-term quality-of-life of patients supported by extracorporeal membrane oxygenation for refractory cardiogenic shock. Crit Care Med 2008;36:1404-11.

15. Mégarbane B, Deye N, Aout M, Malissin I, Résière D, Haouache H, et al. Usefulness of routine laboratory parameters in the decision to treat refractory cardiac arrest with extracorporeal life support. Resuscitation 2011;82:1154-61

16. Rousse N, Juthier F, Pinçon C, Hysi I, Banfi C, Robin E, et al. ECMO as a bridge to decision: Recovery, VAD, or heart transplantation? Int $\mathrm{J}$ Cardiol 2015;187:620-7.

17. Pappalardo F, Pieri M, Arnaez Corada B, Ajello S, Melisurgo G, De Bonis $\mathrm{M}$, et al. Timing and strategy for weaning from venoarterial ECMO are complex issues. J Cardiothorac Vasc Anesth 2015;29:906-11.

18. Demondion P, Fournel L, Golmard JL, Niculescu M, Pavie A, Leprince P. Predictors of 30-day mortality and outcome in cases of myocardial infarction with cardiogenic shock treated by extracorporeal life support. Eur J Cardiothorac Surg 2014;45:47-54.

19. Chung SY, Sheu JJ, Lin YJ, Sun CK, Chang LT, Chen YL, et al. Outcome of patients with profound cardiogenic shock after cardiopulmonary resuscitation and prompt extracorporeal membrane oxygenation support. A single-center observational study. Circ J 2012;76:1385-92.

20. Lin CY, Tsai FC, Tian YC, Jenq CC, Chen YC, Fang JT, et al. Evaluation of outcome scoring systems for patients on extracorporeal membrane oxygenation. Ann Thorac Surg 2007;84:1256-62.

21. Hsu PS, Chen JL, Hong GJ, Tsai YT, Lin CY, Lee CY, et al. Extracorporeal membrane oxygenation for refractory cardiogenic shock after cardiac surgery: Predictors of early mortality and outcome from 51 adult patients. Eur J Cardiothorac Surg 2010;37:328-33.
22. Guttendorf J, Boujoukos AJ, Ren D, Rosenzweig MQ, Hravnak M. Discharge outcome in adults treated with extracorporeal membrane oxygenation. Am J Crit Care 2014;23:365-77.

23. Burrell AJ, Pellegrino VA, Wolfe R, Wong WK, Cooper DJ, Kaye DM, et al. Long-term survival of adults with cardiogenic shock after venoarterial extracorporeal membrane oxygenation. J Crit Care 2015;30:949-56

24. Chen JS, Ko WJ, Yu HY, Lai LP, Huang SC, Chi NH, et al. Analysis of the outcome for patients experiencing myocardial infarction and cardiopulmonary resuscitation refractory to conventional therapies necessitating extracorporeal life support rescue. Crit Care Med 2006;34:950-7.

25. Schmidt M, Burrell A, Roberts L, Bailey M, Sheldrake J, Rycus PT, et al. Predicting survival after ECMO for refractory cardiogenic shock: The survival after veno-arterial-ECMO (SAVE)-score. Eur Heart J 2015;36:2246-56

26. Peigh G, Cavarocchi N, Keith SW, Hirose H. Simple new risk score model for adult cardiac extracorporeal membrane oxygenation: Simple cardiac ECMO score. J Surg Res 2015;198:273-9.

27. Mehra MR, Kobashigawa J, Starling R, Russell S, Uber PA, Parameshwar $\mathrm{J}$, et al. Listing criteria for heart transplantation: International Society for Heart and Lung transplantation guidelines for the care of cardiac transplant candidates-2006. J Heart Lung Transplant 2006;25:1024-42.

28. Le Gall JR, Lemeshow S, Saulnier F. A new simplified acute physiology score (SAPS II) based on a European/North American multicenter study. JAMA 1993;270:2957-63.

29. Shirakabe A, Nozaki A, Hata N, Kobayashi N, Shinada T, Tomita K, et al. Predictive score for survival after percutaneous cardiopulmonary support in cardiovascular disease patients- evaluation of pre-procedural information. Circ J 2013;77:2064-72.

30. Schmidt M, Zogheib E, Rozé H, Repesse X, Lebreton G, Luyt CE, et al. The PRESERVE mortality risk score and analysis of long-term outcomes after extracorporeal membrane oxygenation for severe acute respiratory distress syndrome. Intensive Care Med 2013;39:1704-13

31. Pappalardo F, Pieri M, Greco T, Patroniti N, Pesenti A, Arcadipane A, et al. Predicting mortality risk in patients undergoing venovenous ECMO for ARDS due to influenza A(H1N1) pneumonia: The ECMOnet score. Intensive Care Med 2013;39:275-81

32. Park SB, Yang JH, Park TK, Cho YH, Sung K, Chung CR, et al. Developing a risk prediction model for survival to discharge in cardiac arrest patients who undergo extracorporeal membrane oxygenation. Int J Cardiol 2014;177:1031-5.

33. Aissaoui N, Luyt CE, Leprince P, Trouillet JL, Léger P, Pavie A, et al. Predictors of successful extracorporeal membrane oxygenation (ECMO) weaning after assistance for refractory cardiogenic shock. Intensive Care Med 2011;37:1738-45.

34. Chang WW, Tsai FC, Tsai TY, Chang CH, Jenq CC, Chang MY, et al. Predictors of mortality in patients successfully weaned from extracorporeal membrane oxygenation. PLoS One 2012;7:e42687.

35. Platts DG, Sedgwick JF, Burstow DJ, Mullany DV, Fraser JF. The role of echocardiography in the management of patients supported by extracorporeal membrane oxygenation. J Am Soc Echocardiogr 2012;25:131-41

36. Cavarocchi NC, Pitcher HT, Yang Q, Karbowski P, Miessau J, Hastings HM, et al. Weaning of extracorporeal membrane oxygenation using continuous hemodynamic transesophageal echocardiography. J Thorac Cardiovasc Surg 2013;146:1474-9.

37. Distelmaier K, Niessner A, Haider D, Lang IM, Heinz G, Maurer G, et al. Long-term mortality in patients with chronic obstructive pulmonary disease following extracorporeal membrane oxygenation for cardiac assist after cardiovascular surgery. Intensive Care Med 2013;39:1444-51. 